\title{
Persepsi Petani terhadap Implementasi Teknologi Informasi dan Komunikasi dalam Penyuluhan Pertanian
}

\section{Farmer's Perception on Information and Communication Technology Implementation in Agricultural Extension}

\author{
Zulham Sirajuddin*), Pepi Liskawati Kamba
}

Universitas Ichsan Gorontalo, Gorontalo 96115, Indonesia

${ }^{*}$ E-mail korespondensi: zulham.sirajuddin@gmail.com

Diterima: 29 September 2020 | Disetujui: 28 Juli 2021 | Publikasi Online: 29 Juli 2021

\section{ABSTRACT}

In the era of Industry 4.0, the use of Information and Communication Technology (ICT) is vital in agricultural extension. However, there are still variations in the use and adoption of ICTs at the farmer levels as not every region can optimize the use of ICT in agricultural extension. This study aims to identify the diversity of access to ICT by farmers, and identify farmers' perceptions of the use of ICT. This study used a survey method with quantitative descriptive data analysis, distributed to 73 sample respondents. The questionnaire was compiled using the Technology Acceptance Model (TAM) theory lens, using two aspects in analyzing technology acceptance: perceived usefulness and perceived ease of use. The results showed that the use of smartphones by farmers was high with access ownership above 60\%. ICT is well accepted by respondents compared to conventional media. There is a significant relationship between the education level of farmers and perceived ease of use, with a correlation coefficient of .322. It can be concluded that smartphones have considerable potential to be used in agricultural extension, and there is a need of strategy to improve the ease of use of smartphones for farmers with low education level.

Kata kunci: Agricultural extension, ICT, TAM

\section{ABSTRAK}

Pada era Industri 4.0, penggunaan Teknologi Informasi dan Komunikasi (TIK) cukup vital dalam penyuluhan pertanian, utamanya sebagai saluran informasi yang dibutuhkan petani. Meski begitu, masih terdapat keberagaman penggunaan maupun adopsi TIK baik di tingkat penyuluh maupun petani sehingga tidak di setiap daerah dapat mengoptimalkan penggunaan TIK dalam penyuluhan pertanian. Penelitian ini bertujuan untuk mengidentifikasi keberagaman akses TIK oleh petani, dan mengidentifikasi persepsi petani terhadap penggunaan TIK. Penelitian ini menggunakan metode survei dengan analisis data deskriptif kuantitatif, yang disebarkan kepada 73 responden sampel. Kuesioner disusun dengan menggunakan lensa teori Technology Acceptance Model (TAM), yang menggunakan dua aspek dalam menganalisis penerimaan teknologi yaitu perceived usefulness dan perceived ease of use. Hasil penelitian menunjukkan bahwa penggunaan smartphone oleh petani di lokasi penelitian cukup tinggi dengan kepemilikan akses di atas $60 \%$. Penerimaan responden terhadap TIK melalui perceived usefulness dan perceived ease of use cukup baik dibanding media konvensional. Terdapat hubungan positif yang sangat signifikan pada level .001 antara tingkat pendidikan petani dengan perceived ease of use, dengan koefisien korelasi sebesar .322. Dapat disimpulkan bahwa smartphone sebagai alat TIK memiliki potensi yang cukup besar untuk dapat digunakan dalam penyuluhan pertanian, dan perlu ada strategi untuk meningkatkan kemudahan penggunaan smartphone pada petani yang berpendidikan rendah.

Kata kunci: Penyuluhan pertanian, teknologi informasi dan komunikasi, technology acceptance model

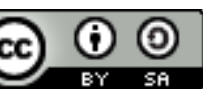

Content from this work may be used under the terms of the Creative Commons Attribution-ShareAlike 4.0 International. Any further distribution of this work must maintain attribution to the author(s) and the title of the work, journal citation and DOI.

Published under Department of Communication and Community Development Science, IPB University and in association with Perhimpunan Ahli Penyuluhan Pembangunan Indonesia.

E-ISSN: 2442-4110 | P-ISSN: 1858-2664 


\section{PENDAHULUAN}

Revolusi Industri 4.0 memiliki dampak yang cukup besar bukan hanya dibidang industri manufaktur tetapi juga bidang pertanian di seluruh dunia. Implikasinya, terjadi peningkatan penggunaan Teknologi Informasi dan Komunikasi (TIK) dibeberapa aspek pembangunan pertanian, diantaranya adalah penggunaan TIK dalam penyuluhan pertanian (Sirajuddin, 2019). Sebagai contoh, penyuluhan pertanian di Amerika Serikat mengintegrasikan penggunaan TIK ke dalam penyuluhan pertanian (cooperative extension system), dimana aplikasi ini diberi nama eXtension (Taylor \& Miller, 2016). Afrika Selatan merupakan salah satu negara yang mengimplementasikan TIK dalam penyuluhan pertaniannya melalui aplikasi Farmbook yang didesain untuk membantu petani dalam memperoleh informasi yang dibutuhkan (Tata \& McNamara, 2017). Di Asia, penggunaan TIK juga kini semakin banyak digunakan dalam penyuluhan pertanian misalnya di India dengan aplikasi e-Choupal (Kim, Chitnis, Vasanti, \& Singhal, 2007) maupun di Cina dengan 3 inl service Fujian (Zhang, Wang, \& Duan, 2016). Kameswari, Kishore, dan Gupta (2011) berpendapat bahwa penggunaan TIK dalam bidang pertanian salah satunya bertujuan untuk membantu petani dalam berkomunikasi dengan pembeli komoditas yang diproduksi petani. Penggunaan TIK dalam penyuluhan pertanian di India dalam bentuk aplikasi e-Choupal dianggap sebagai salah satu aspek keberhasilan penyuluhan pertanian digital di India (Bansal \& Sharma, 2012).

Di Indonesia, penggunaan TIK dalam penyuluhan pertanian salah satunya ditunjukkan melalui implementasi sistem penyuluhan pertanian berbasis teknologi informasi yaitu Cyber-Extension, yang diluncurkan oleh Kementerian Pertanian untuk meningkatkan kinerja penyuluh pertanian dalam melayani masyarakat pertanian, utamanya dalam memberikan informasi yang cepat, akurat dan terpercaya (Sirajuddin \& Martin, 2019). Penggunaan TIK oleh penyuluh pertanian, utamanya dalam pengelolaan informasi cukup membantu penyuluh dalam meningkatkan kinerjanya dalam melayani masyarakat petani (Purwatiningsih, Fatchiya, \& Mulyandari, 2018). Hal ini menunjukkan bahwa penggunaan TIK cukup vital dalam penyuluhan pertanian, utamanya sebagai saluran informasi baik yang dibutuhkan oleh petani maupun penyuluh pertanian.

Penyuluhan pertanian sebagai sarana belajar petani menitikberatkan salah satunya pada diseminasi informasi untuk mendukung keputusan petani. Proses diseminasi ini, menurut Ashari, Sharifuddin, dan Abidin (2018), sangat vital dalam mendukung adopsi teknologi di tingkat petani. Sebagaimana diteliti oleh Ismilaili, Purnaningsih, dan Asngari (2015) misalnya, yang menemukan bahwa penerimaan petani terhadap paket teknologi yang ditawarkan penyuluh dalam Sekolah Lapang - Pengelolaan Tanaman Terpadu (SL-PTT), dipengaruhi secara signifikan oleh akses petani terhadap informasi. Meski dalam penyuluhan pertanian, pertemuan tatap muka (face-to-face) merupakan kekuatan utama dalam pertukaran informasi, alur informasi dalam bentuk digital melalui penggunaan TIK tetap menjadi aspek penting yang bahkan saling melengkapi antara tatap muka dan online (Materia, Giarè, \& Klerkx, 2015). TIK berfungsi sebagai media digital yang membantu percepatan penyebaran informasi melalui dunia maya sehingga pengguna informasi dapat memanfaatkan informasi yang cepat dan akurat untuk kebutuhannya (Helmy, Sumardjo, Purnaningsih, \& Tjitropranoto, 2013). Hal ini menunjukkan bahwa peran TIK sebagai media penyebaran informasi digital secara luas sangat penting dalam penyuluhan pertanian.

Meski begitu, masih terdapat keberagaman penggunaan maupun adopsi TIK baik di tingkat penyuluh maupun petani di Indonesia, sehingga tidak di setiap daerah dapat mengoptimalkan penggunaan TIK dalam penyuluhan pertanian utamanya dalam bertukar informasi yang dibutuhkan dalam pengambilan keputusan dalam pengelolaan lahan. Salah satu alasannya adalah kurangnya kemampuan SDM pengguna TIK sehingga belum memahami manfaat dari penggunaan TIK (Mulyandari, Sumardjo, Lubis, \& Panjaitan, 2010). Alasan lain adalah masih rendahnya penggunaan alat TIK di pedesaan. Sebagaimana dilaporkan oleh Asosiasi Jasa Penyelenggara Internet (AJPII) dalam survei yang dilakukan pada tahun 2018 menemukan bahwa kepemilikan penduduk desa terhadap alat TIK seperti smartphone, komputer dan sebagainya masih dibawah 50\% (AJPII, 2018). Oleh sebab itu, upaya untuk meningkatkan kemampuan pengguna TIK di tingkat petani perlu dilakukan untuk mengoptimalkan penggunaan TIK sehingga pertukaran informasi pertanian dapat lebih cepat dilakukan hingga di tingkat petani.

Kurangnya kemampuan maupun penerimaan (acceptance) pengguna dalam memanfaatkan TIK dapat dianalisis melalui teori Technology Acceptance Model (TAM) yang memandang bahwa terdapat dua determinan yang mempengaruhi penerimaan seseorang terhadap teknologi informasi. Kedua determinan 
tersebut yakni perceived usefulness (PU), yang didefenisikan sebagai persepsi bahwa penggunaan sebuah sistem TIK dapat memberikan kegunaan langsung dalam meningkatkan kinerja pengguna, dan perceived ease of use (PEU), yakni persepsi bahwa penggunaan sebuah sistem TIK dipandang tidak rumit untuk dilakukan atau mudah untuk digunakan oleh pengguna TIK (Davis, 1989). Model TAM inilah yang digunakan dalam penelitian ini sebagai lensa teori untuk mendeskripsikan penggunaan TIK di tingkat petani, sebab meski telah terdapat beberapa penelitian mengenai adopsi TIK pada penyuluhan pertanian Indonesia, masih sangat minim peneliti yang menggunakan TAM sebagai lensa teori dalam penelitiannya.

Memahami seberapa jauh penerimaan petani sebagai pengguna TIK sangat penting untuk mendesain strategi penyuluhan berbasis digital, utamanya dalam peningkatan penggunaan teknologi informasi di era Industri 4.0 di Indonesia. Oleh karena itu, melihat pentingnya untuk menganalisis penggunaan dan penerimaan TIK oleh petani, maka penelitian ini merumuskan tujuan penelitian yaitu: (1) untuk mengidentifikasi keragaman akses TIK oleh petani, (2) untuk mengidentifikasi persepsi petani terhadap penggunaan TIK, dan (3) untuk mengetahui perbandingan dan hubungan antara karakteristik petani dengan persepsi terhadap TIK.

\section{METODE PENELITIAN}

Metode yang digunakan dalam penelitian ini adalah metode survei dengan analisis data deskriptif kuantitatif. Populasi penelitian ini adalah 270 petani di Desa Milangodaa, Kabupaten Bolaang Mongondow Selatan, Provinsi Sulawesi Utara. Sampel ditentukan pada confidence level $95 \%$ dan margin of error $10 \%$ yakni sebanyak 73 responden sampel. Jumlah sampel yang digunakan tersebut disesuaikan dengan kemampuan peneliti serta kondisi geografis lokasi penelitian. Data dikumpulkan melalui penggunaan kuisioner yang disebarkan melalui wawancara langsung terhadap responden yang dilakukan selama bulan Desember 2019 hingga Februari 2020. Kuisioner disusun untuk mengumpulkan data demografi, keragaman frekuensi penggunaan TIK, serta persepsi petani terhadap penggunaan TIK. Keragaman frekuensi penggunaan terhadap TIK diukur dengan menggunakan skala Likert empat tingkat dengan pilihan jawaban yaitu: tidak punya, jarang digunakan, kadang-kadang, dan sering.

Akses terhadap alat TIK yang dimaksud adalah akses terhadap smartphone dan komputer/laptop. Persepsi responden terhadap penggunaan TIK diukur dengan menggunakan Skala Likert lima tingkat dengan pilihan jawaban yaitu; sangat setuju, setuju, netral, tidak setuju, dan sangat tidak setuju. Dalam penyusunan item pernyataan, penelitian ini menggunakan lensa teori Technology Acceptance Model (TAM), dimana terdapat dua aspek dalam menganalisis penerimaan teknologi pada pengguna yaitu perceived usefulness (PU) dan perceived ease of use (PEU) yang dapat mempengaruhi pengguna untuk mengadopsi TIK (Davis, 1989). Masing-masing aspek diukur melalui lima item pernyataan dalam kuisioner sebagaimana terdapat pada Tabel 1. Item-item tersebut lalu dianalisis reliabilitasnya untuk melihat apakah konstruk yang digunakan baik untuk PU maupun PEU cukup reliabel.

Tabel 1. Item dalam konstruk perceived usefulness dan perceived ease of use.

\begin{tabular}{llc}
\hline \multicolumn{1}{c}{ Konstruk } & \multicolumn{1}{c}{ Item } & Cronbach's alpha \\
\hline Perceived usefulness & TIK berguna untuk mencari informasi yang saya butuhkan. & .902 \\
& Pencarian informasi yang saya lakukan lebih cepat dalam & \\
& menggunakan TIK. & \\
& Menggunakan TIK ketika mencari informasi sangat \\
& menghemat waktu. & \\
& Informasi yang tersedia pada TIK sangat beragam. \\
& Informasi yang tersedia pada TIK lebih terkini dan baru. \\
& TIK cukup mudah digunakan. \\
& Tidak perlu belajar lama untuk mengetahui cara \\
& menggunakan TIK. \\
& Saya tidak pernah mengalami kesulitan ketika menggunakan \\
& TIK. \\
& Saya tidak pernah kebingungan ketika menggunakan TIK. \\
& Saya sangat jarang membuat kesalahan saat menggunakan \\
& TIK.
\end{tabular}

Sumber: Adaptasi dari Davis, 1989

Jurnal Penyuluhan | Vol. 17 (02) 2021 | 138 
Hasil uji reliabilitas menunjukkan bahwa nilai Cronbach's Aplha pada PU adalah .902 dan PEU adalah 1.00. Nilai Cronbach's Alpha yang lebih besar dari .70 menunjukkan bahwa item tersebut memiliki reliabilitas pada konstruk yang kuat (Morgan, Barrett, Leech, \& Gloeckner, 2019). Adapun pada aspek PEU, dimana nilai Cronbach's Alpha adalah 1.00, menunjukkan bahwa kelima item dalam skala memiliki korelasi sempurna sehingga item manapun mengukur konstruk sebagaimana pengukuran pada item satu sama lainnya (Lavrakas, 2012), sehingga kelima item dapat dipertimbangkan untuk digunakan baik satu maupun seluruhnya dalam pengukuran konstruk PEU. Data kemudian dianalisis dengan menggunakan aplikasi SPSS versi 23 melalui uji T independen (Independent sample T-test) untuk uji perbandingan dua kelompok, serta uji korelasi Pearson product moment dan Spearman rho untuk uji hubungan antara dua variabel.

\section{HASIL DAN PEMBAHASAN}

\section{Karakteristik Responden}

Penelitian ini dilakukan di Desa Milangodaa, Kabupaten Bolaang Mongondow Selatan, Provinsi Sulawesi Utara. Karakteristik responden, sebagaimana ditunjukkan pada Tabel 2 merupakan keragaman demografi sosial ekonomi responden yakni termasuk usia, jenjang pendidikan, tanggungan keluarga, dan keaktifan dalam kelompok tani. Hasil pengambilan data menunjukkan bahwa sebagian besar responden berusia di bawah 50 tahun. Hal ini menunjukkan bahwa petani di Desa Milangodaa didominasi oleh petani yang masih berusia cukup muda. Sementara itu, mayoritas responden memiliki jenjang pendidikan terakhir tidak tamat Sekolah Dasar (SD), sementara sebagian lainnya memiliki jenjang pendidikan tamat SD, dan hanya satu orang responden yang menamatkan pendidikan Sarjana (S1). Hal ini menunjukkan rendahnya tingkat pendidikan petani responden di Desa Milangodaa. Aldosari, Al Shunaifi, Ullah, Muddassir, dan Noor (2019) berpandangan bahwa umur memiliki korelasi dengan aplikasi TIK yang digunakan oleh petani.

Tabel 2. Karakteristik Responden

\begin{tabular}{lcc}
\hline \multicolumn{1}{c}{ Karakteristik } & Kategori \\
\hline Usia & $<4(74 \%)$ & $\geq 50$ \\
& & $19(26 \%)$ \\
Pendidikan & Tidak lulus SD & Lulus SD \\
& $50(68,5 \%)$ & $23(31,5 \%)$ \\
Tanggungan keluarga & $\leq 3$ & $\geq 4$ \\
& $36(49,3 \%)$ & $37(50,7 \%)$ \\
Keaktifan dalam KT & Kurang aktif & Cukup aktif \\
Sumber: Data primer setelah diolah, 2020 & $12(16,4 \%)$ & $61(83,6 \%)$ \\
\hline
\end{tabular}

Pada Tabel 2 terlihat bahwa umumnya responden memiliki 3 (tiga) tanggungan keluarga. Hal ini memperlihatkan bahwa kebanyakan responden memiliki ukuran keluarga yang tidak besar. Sehubungan dengan akses terhadap alat TIK, keberadaan anggota keluarga cukup menunjang akses petani terhadap alat TIK seperti smartphone ataupun laptop/komputer, sebab seringkali dalam satu keluarga petani terdapat dua atau lebih alat TIK yang dapat digunakan (Subejo et al., 2018). Hasil penelitian ini juga menujukkan bahwa mayoritas responden cukup aktif dalam kelompok tani. Hal tersebut mengindikasikan bahwa sebagian besar petani cukup terlibat dalam kegiatan yang dilakukan oleh kelompok tani masing-masing. Sebagai unit sosial, kelompok tani menjadi wadah bagi petani untuk saling belajar satu sama lain, termasuk dengan sesama petani.

\section{Akses Terhadap TIK}

Hasil olah data menunjukkan keberagaman akses petani terhadap media TIK yaitu smartphone, dan komputer/laptop. Hal tersebut ditunjukkan pada Tabel 3 sebagai berikut. 
Tabel 3. Keragaman akses responden terhadap media TIK

\begin{tabular}{lcccc}
\hline \multirow{2}{*}{ Akses terhadap TIK } & \multicolumn{2}{c}{ Smartphone } & \multicolumn{2}{c}{ Komputer/Laptop } \\
\cline { 2 - 5 } & N & \% & n & \% \\
\hline Punya akses & 44 & 60,3 & 1 & 1,4 \\
Tidak punya & 29 & 39,7 & 72 & 98,6 \\
\hline
\end{tabular}

Sumber: Data primer setelah diolah, 2020

Tabel 3 menunjukkan bahwa mayoritas petani memiliki akses terhadap smartphone, namun sebagian besar tidak memiliki akses terhadap komputer. Hal ini menunjukkan bahwa penggunaan smartphone oleh petani di lokasi penelitian sudah cukup tinggi dengan kepemilikan akses mencapai hingga 60,3\%. Akses ini lebih tinggi dibandingkan kepemilikan smartphone oleh penduduk di wilayah pedesaan di tingkat nasional yang hanya mencapai 42,06\% (AJPII, 2018). Sementara itu, akses terhadap komputer masih sangat rendah dengan persentase akses yang hanya mencapai $1,4 \%$, jauh lebih rendah dibanding nasional dimana tingkat kepemilikan komputer oleh penduduk pedesaan mencapai 23,83\%. Hasil tersebut menunjukkan bahwa penggunaan smartphone di tingkat petani masih jauh lebih populer dibandingkan komputer ataupun laptop. Kepemilikan smartphone dalam keluarga petani di desa menguntungkan sebab selain digunakan untuk mengakses informasi dunia maya (internet), fungsi dasar smartphone juga sebagai alat komunikasi audio dua arah yakni sebagai telepon genggam. Dengan memiliki smartphone, petani bukan hanya memiliki perangkat TIK untuk akses internet, namun juga sekaligus memiliki telepon genggam untuk berkomunikasi dengan orang lain.

Cukup tingginya akses terhadap smartphone tersebut menunjukkan bahwa smartphone berpotensi untuk digunakan sebagai media penyuluhan berbasis internet, sementara komputer dan laptop saat ini masih belum berpotensi untuk digunakan sebagai alat TIK dalam media penyuluhan akibat akses petani terhadap kompouter maupun laptop yang masih sangat rendah. Hal ini mengindikasikan pentingnya pemanfaatan aplikasi pada smartphone baik yang berbasis android maupun iOS, utamanya pada aplikasi yang berhubungan dengan diseminasi informasi pertanian. Di Indonesia, terdapat beberapa aplikasi pemberi informasi pertanian yang dapat diakses melalui smartphone berbasis android seperti Takesi yang digunakan untuk manajemen ternak, maupun iTani yang merupakan aplikasi perpustakaan digital pemberi informasi bagi petani (Sirajuddin, 2019). Internet selain mampu menyediakan informasi yang lebih luas sebab tanpa perlu kontak fisik, juga dapat menyalurkan informasi jauh lebih cepat dibanding media konvensional.

Oleh karena itu, perlu untuk mengidentifikasi kebutuhan informasi pertanian yang dapat dimanfaatkan oleh petani sehingga penggunaan TIK dapat lebih optimal, sebab kebutuhan informasi dapat beragam antara satu petani dengan petani lainnya. Di India misalnya, akses informasi pertanian digunakan petani untuk mengetahui cara bercocok tanam, mengakses harga komoditi di pasaran, bahkan untuk mendapatkan informasi cuaca (Kameswari et al., 2011), sementara di Afrika, TIK digunakan petani untuk mendapatkan informasi produktivitas pangan serta menganalisis keuntungan agribisnis (Tata \& McNamara, 2017).

\section{Persepsi Petani terhadap TIK}

Penelitian ini menganalisis bagaimana penerimaan responden terhadap TIK yang ditunjukkan melalui dua aspek persepsi yakni PU dan PEU, dimana masing-masing konstruk PU dan PEU memiliki lima item yang mengindikasikan kegunaan (usefulness) pada PU maupun kemudahan (easiness) pada PEU untuk penggunaan alat TIK. Hasil analisis persepsi petani terhadap PE dan PEU memperlihatkan bahwa baik PU maupun PEU, responden menunjukkan persepsi yang positif, dimana sebagian besar responden berpendapat bahwa TIK berguna bagi mereka dalam mencari informasi dan TIK mudah dipelajari. Skor tertinggi pada PU terdapat pada item "Pencarian informasi yang saya lakukan lebih cepat dalam menggunakan TIK", dan "Menggunakan TIK ketika mencari informasi sangat menghemat waktu". Responden menganggap bahwa penggunaan media TIK berguna utamanya untuk memperoleh beragam informasi terkini yang dibutuhkan dengan lebih cepat dibandingkan dengan media konvensional yang biasanya digunakan dalam penyuluhan pertanian seperti brosur, pamflet, ataupun majalah. Kecepatan akses pada media internet dianggap lebih menghemat waktu oleh petani sebab tidak perlu menunggu akses fisik terhadap media berita yang dibutuhkan. Informasi yang tersedia secara online juga dianggap lebih beragam sehingga terdapat banyak pilihan informasi bagi petani untuk memperkuat keputusan yang akan diambilnya. Hasil ini sesuai dengan penelitian yang dilakukan oleh Aldosari dkk. (2019), 
dimana dalam penelitiannya ditemukan bahwa mayoritas petani di Khyber Pakhtunkhwa, Pakistan Utara setuju bahwa internet merupakan salah satu sumber informasi pertanian yang berguna bagi petani.

Dari sisi kemudahan, penggunaan media TIK dipandang petani cukup mudah dan tidak membingungkan. Hal ini terlihat pada skor persepsi petani pada kelima item mengenai aspek PEU penggunaan alat TIK, dimana petani umumnya setuju bahwa TIK mudah digunakan. Petani mudah belajar menggunakan alat TIK sebab fitur-fiturnya yang tidak rumit dan udah difahami, sehingga tidak butuh waktu yang lama bagi petani untuk mempelajari penggunaannya. Dalam mengakses informasi melalui alat maupun program TIK, petani sangat memperhitungkan kemudahan dan kejelasan penggunaan agar dapat memuaskan, utamanya dalam menggabungkan media baik audio maupun visual dalam aplikasi (Ramkumar, Garforth, Rao, \& Heffernan, 2007). Kemudahan menggunakan alat TIK dapat berdampak positif pada kemudahan mengakses informasi pertanian yang dibutuhkan petani. Kebutuhan petani akan ketersediaan informasi merupakan hal yang sangat vital dalam penyuluhan pertanian, sebab dengan adanya informasi yang akurat, petani dapat terbantu dalam pengambilan keputusan. Hal ini sejalan dengan penelitian Ismilaili, Purnaningsih, dan Asngari (2015), yang menyatakan bahwa akses informasi oleh petani berpengaruh signifikan terhadap adopsi teknologi dalam penyuluhan pertanian. Mayasari, Muljono, dan Fatchiya (2020) menunjukkan bahwa pengguna aplikasi iTani menganggap kemudahan akses menjadi sumber kepuasan utama pengguna aplikasi. Hal ini juga didukung oleh penelitian yang dilakukan oleh Suratini, Muljono, dan Tri Wibowo (2021), bahwa kemudahan mengakses informasi berpengaruh nyata terhadap penggunaan TIK dalam penyuluhan pertanian.

\section{Perbandingan dan Hubungan Antara Karakteristik Petani dengan Persepsi Terhadap TIK}

Penelitian ini melihat apakah terdapat perbedaan persepsi petani responden jika dikomparasikan dalam perbedaan karakteristik petani, yakni keberagaman akses terhadap TIK, tingkat pendidikan responden serta keaktifan responden dalam kelompok tani, serta melihat apakah terdapat hubungan antara karakteristik dengan persepsi petani. Analisis yang digunakan adalah independent t-test untuk perbandingan antar dua kelompok, dan korelasi untuk hubungan antara dua variabel.

Tabel 4. Hasil perbandingan persepsi petani melalui perbandingan karakteristik pada Uji-T

\begin{tabular}{|c|c|c|}
\hline Perbandingan kelompok karakteristik & Uji-T Independen & Keterangan \\
\hline \multicolumn{3}{|l|}{ Akses terhadap alat TIK } \\
\hline PU & .500 & Tidak signifikan \\
\hline PEU & .160 & Tidak signifikan \\
\hline \multicolumn{3}{|l|}{ Keaktifan dalam kelompok tani } \\
\hline PU & .504 & Tidak signifikan \\
\hline PEU & .446 & Tidak signifikan \\
\hline
\end{tabular}

Sumber: Data primer setelah diolah, 2020

Hasil analisis data melalui uji-T independen yang ditunjukkan oleh Tabel 4 mengindikasikan bahwa persepsi petani responden tidak berbeda secara signifikan pada dua kelompok yakni petani yang memiliki akses terhadap TIK maupun yang tidak memiliki akses terhadap TIK sehingga dapat disimpulkan bahwa kepemilikan akses TIK tidak berarti bahwa persepsi terhadap TIK juga semakin baik ataupun semakin buruk dibandingkan dengan orang yang tidak memiliki akses terhadap TIK. Selain itu, uji-T independen yang dilakukan dengan menggunakan perbedaan keaktifan dalam kelompok tani juga menunjukkan bahwa tidak terdapat perbedaan persepsi yang signifikan antara petani yang cukup aktif maupun yang kurang aktif dalam kelompok tani.

Tabel 5. Hubungan antara karakteristik petani dengan persepsi petani

\begin{tabular}{lccc}
\hline \multicolumn{1}{c}{ Karakteristik } & $\begin{array}{c}\text { Technology Acceptance Model } \\
\text { PU }\end{array}$ & PEU & Keterangan \\
\hline Umur & & & \\
$\quad$ Pearson correlation & .009 & -.044 & \\
$\quad$ Sig. & .942 & .711 & Tidak signifikan \\
Tingkat pendidikan & & & \\
$\quad$ Spearman correlation & .223 & .322 & \\
$\quad$ Sig. & .058 & $.006 *$ & Signifikan \\
*Signifikan pada tingkatan alpha .01 & & &
\end{tabular}


Tabel 5 menunjukkan hasil uji korelasi Pearson yang memperlihatkan bahwa tidak terdapat hubungan yang signifikan antara usia petani dengan persepsi tentang kegunaan (PU) dan persepsi tentang kemudahan (PEU) penggunaan TIK. Hal ini berarti bahwa usia petani tidak memberikan pengaruh terhadap penerimaan petani pada penggunaan TIK. Hasil ini berbeda dengan hasil penelitian yang ditunjukkan oleh Subejo dkk. (2018), yang menunjukkan bahwa usia petani merupakan salah satu faktor determinan terhadap pemanfaatan TIK untuk pengembangan komoditas pertanian komersial di Yogyakarta.

Hasil uji korelasi Spearman Rho antara variabel tingkat pendidikan dengan persepsi tentang kegunaan (PU) dan persepsi tentang kemudahan (PEU) yang terlihat pada Tabel 6 menunjukkan bahwa tidak terdapat hubungan yang signifikan antara tingkat pendidikan petani dengan persepsi tentang kegunaan penggunaan alat TIK. Meski begitu, terdapat hubungan positif yang sangat signifikan pada level .001 antara tingkat pendidikan petani dengan persepsi tentang kemudahan penggunaan alat TIK dengan koefisien korelasi sebesar .322. Hal ini menunjukkan bahwa semakin tinggi tingkat pendidikan petani responden, semakin tinggi pula persepsi mereka mengenai kemudahan penggunaan alat TIK. Adapun efek hubungan tersebut yakni .322 menunjukkan kekuatan hubungan yang medium (Cohen, 2013). Hubungan antara antara tingkat pendidikan petani dengan PEU mengenai penggunaan alat TIK ini sejalan dengan penelitian yang dilakukan oleh Michels, Bonke, \& Mußhoff (2019), dimana dalam penelitiannya menunjukkan bahwa terdapat hubungan antara tingkat pendidikan petani dengan PEU penggunaan smartphone untuk manajemen ternak di Jerman. Selain itu, Mittal dan Mehar (2016) juga menunjukkan bahwa semakin tinggi tingkat pendidikan petani di India, semakin besar potensi petani untuk mengadopsi penggunaan TIK untuk mendapatkan informasi yang dibutuhkannya.

\section{KESIMPULAN}

Hasil penelitian ini menunjukkan bahwa diantara keberagaman akses petani terhadap alat TIK, smartphone paling banyak diakses. Smartphone memiliki potensi yang cukup besar untuk dapat digunakan dalam penyuluhan pertanian sebab akses terhadap smartphone yang cukup tinggi di kalangan petani. Oleh karena itu, dapat disimpulkan bahwa penyuluhan pertanian ke depan mesti mempertimbangkan desain strategi komunikasi penyuluhan yang memanfaatkan aplikasi yang mudah diakses melalui smartphone. Penelitian ini juga menunjukkan bahwa petani memiliki persepsi yang baik mengenai kegunaan (PU) penggunaan TIK maupun kemudahan (PEU) penggunaan alat TIK. Lebih jauh, penelitian ini menunjukkan bahwa terdapat korelasi positif antara tingkat pendidikan dengan persepsi petani mengenai kemudahan penggunaan alat TIK (PEU), dimana hal ini mengindikasikan bahwa perlu ada strategi untuk meningkatkan kemudahan penggunaan smartphone utamanya pada petani yang berpendidikan rendah.

\section{DAFTAR PUSTAKA}

Aldosari, F., Al Shunaifi, M. S., Ullah, M. A., Muddassir, M., \& Noor, M. A. (2019). Farmers' perceptions regarding the use of Information and Communication Technology (ICT) in Khyber Pakhtunkhwa, Northern Pakistan. Journal of the Saudi Society of Agricultural Sciences, 18(2), 211-217. https://doi.org/10.1016/j.jssas.2017.05.004

Ashari, Sharifuddin, \& Abidin, M. Z. (2018). Factors determining organic farming adoption: International research results and lesson learned for Indonesia. Forum Penelitian Agro Ekonomi, 35(1), 45-58. https://doi.org/10.21082/fae.v35n1.2017.45-58

Asosiasi Jasa Penyelenggara Internet Indonesia [AJPII]. (2018). Penetrasi dan Perilaku Pengguna Internet Indonesia. Retrieved from https://apjii.or.id/

Bansal, R., \& Sharma, A. K. (2012). E-choupal: Gateway to develop agriculture market. 4D International Journal of IT \& Commerce, 1(1), 87.

Cohen, J. (2013). Statistical Power Analysis for the Behavioral Sciences. In Statistical Power Analysis for the Behavioral Sciences. https://doi.org/10.4324/9780203771587

Davis, F. D. (1989). Perceived usefulness, perceived ease of use, and user acceptance of information technology. MIS Quarterly: Management Information Systems. https://doi.org/10.2307/249008

Helmy, Z., Sumardjo, Purnaningsih, N., \& Tjitropranoto, P. (2013). Cyber Extension in strengthening

Jurnal Penyuluhan | Vol. 17 (02) 2021 | 142 
the extension workers' readiness in the regencies of Bekasi and Kuningan, West Java Province. International Journal of Sciences: Basic and Applied Research (IJSBAR), 8(1), 56-66.

Ismilaili, Purnaningsih, N., \& Asngari, P. (2015). Tingkat adopsi inovasi Pengelolaan Tanaman Terpadu (PTT) padi sawah di Kecamatan Leuwiliang, Kabupaten Bogor. Jurnal Penyuluhan, 11(1), 49-59.

Kameswari, V. L. V., Kishore, D., \& Gupta, V. (2011). ICTs For Agricultural Extension: A Study in the Indian Himalayan Region. The Electronic Journal of Information Systems in Developing Countries. https://doi.org/10.1002/j.1681-4835.2011.tb00339.x

Kim, do K., Chitnis, K., Vasanti, P. N., \& Singhal, A. (2007). Opinion leadership in Indian villages and diffusion of E-Choupal. Journal of Creative Communications, 2(3), 345-360. https://doi.org/10.1177/097325860700200305

Lavrakas, P. (2012). Encyclopedia of Survey Research Methods. In Encyclopedia of Survey Research Methods. https://doi.org/10.4135/9781412963947

Materia, V. C., Giarè, F., \& Klerkx, L. (2015). Increasing Knowledge Flows between the Agricultural Research and Advisory System in Italy: Combining Virtual and Non-virtual Interaction in Communities of Practice. Journal of Agricultural Education and Extension. https://doi.org/10.1080/1389224X.2014.928226

Mayasari, K., Muljono, P., \& Fatchiya, A. (2020). Kepuasan Pengguna Informasi Pertanian Dan Strategi Diseminasi Teknologi Pertanian Melalui Pemanfaatan Aplikasi Itani. Jurnal Penyuluhan, 16(1), 174-184. https://doi.org/10.25015/16202029753

Michels, M., Bonke, V., \& Mußhoff, O. (2019). Adoption of herd management smartphone apps in German dairy farming. The 59th Annual Conference of the German Society of Economic and Social Sciences in Agriculture (GEWISOLA), (September), 25-27. Berlin, Germany: GEWISOLA.

Mittal, S., \& Mehar, M. (2016). Socio-economic Factors Affecting Adoption of Modern Information and Communication Technology by Farmers in India: Analysis Using Multivariate Probit Model. Journal of Agricultural Education and Extension, 22(2), 199-212. https://doi.org/10.1080/1389224X.2014.997255

Morgan, G. A., Barrett, K. C., Leech, N. L., \& Gloeckner, G. W. (2019). IBM SPSS for Introductory Statistics: Use and Interpretation. In IBM SPSS for Introductory Statistics: Use and Interpretation. https://doi.org/10.4324/9780429287657

Mulyandari, R. S. H., Sumardjo, Lubis, D., \& Panjaitan, N. (2010). Implementasi Cyber-Extension dalam Komunikasi Inovasi Pertanian. Informatika Pertanian, 19(2), 17-43.

Purwatiningsih, N. A., Fatchiya, A., \& Mulyandari, R. S. H. (2018). Pemanfaatan Internet dalam Meningkatkan Kinerja Penyuluh Pertanian di Kabupaten Cianjur. Jurnal Penyuluhan, 14(1), 7991. https://doi.org/http://dx.doi.org/10.25015/penyuluhan.v14i1.17173

Ramkumar, S., Garforth, C., Rao, S. V. N., \& Heffernan, C. (2007). Design and Formative Evaluation of an Information Kiosk on Cattle Health for Landless Cattle Owners. The Journal of Agricultural Education and Extension, 13(1), 7-22. https://doi.org/10.1080/13892240601162007

Sirajuddin, Z. (2019). Pemanfaatan teknologi informasi dan komunikasi (TIK) untuk meningkatkan laju adopsi teknologi pertanian. Telaah literatur. Temu Aplikasi Teknologi Dan Seminar Nasional: Akselerasi Inovasi Pertanian Era Industri 4.0 Mendukung Kawasan Pertanian Sejahtera (SAPIRA).

Sirajuddin, Z., \& Martin, R. (2019). Information and Communication Technology (ICT) Proficiency among Extension Agents and its Impact on the Adoption of Cyber-Extension in Indonesia. 35th Annual Conference of AIAEE: Linking, Innovating, Motivating, and Engaging for Resilient Agricultural Systems, 206-208. AIAEE.

Subejo, S., Wati, R. I., Kriska, M., Akhda, N. T., Kristian, A. I., Wimatsari, A. D., \& Penggalih, P. M. (2018). Akses, Penggunaan Dan Faktor Penentu Pemanfaatan Teknologi Informasi Dan Komunikasi Pada Kawasan Pertanian Komersial Untuk Mendukung Ketahanan Pangan Di Perdesaan Yogyakarta. Jurnal Ketahanan Nasional, 24(1), 60. https://doi.org/10.22146/jkn.30270

Suratini, S., Muljono, P., \& Tri Wibowo, C. (2021). Pemanfaatan Media Sosial untuk Mendukung Jurnal Penyuluhan | Vol. 17 (02) 2020 | 143 
Kegiatan Penyuluhan Pertanian di Kabupaten Minahasa Provinsi Sulawesi Utara. Jurnal Penyuluhan, 17(1), 12-24. https://doi.org/10.25015/17202132302

Tata, J. S., \& McNamara, P. E. (2017). Impact of ICT on agricultural extension services delivery: evidence from the Catholic Relief Services SMART skills and Farmbook project in Kenya. Journal of Agricultural Education and Extension, 24(1), 89-110. https://doi.org/10.1080/1389224X.2017.1387160

Taylor, C., \& Miller, G. (2016). Examining eXtension: Diffusion, disruption, and adoption among Iowa State University Extension and Outreach professionals. Journal of Extension, 54(5).

Zhang, Y., Wang, L., \& Duan, Y. (2016). Agricultural information dissemination using ICTs: A review and analysis of information dissemination models in China. Information Processing in Agriculture, 3(1), 17-29. https://doi.org/10.1016/j.inpa.2015.11.002 